\title{
MODELING AND OPTIMIZATION OF
} THE COMPOSITION OF IRON-BASED ALLOYS BY APPROXIMATION WITH NEURAL MODELS AND GENETIC OPTIMIZATION ALGORITHM

\author{
Nikolay Tontchev \\ “Todor Kableshkov" University of Transport, Sofia, Bulgaria

\section{Martin Ivanov} \\ New Bulgarian University of Sofia, Sofia, Bulgaria
}

\section{(c) MESTE NGO}

\begin{abstract}
The research in this paper is intended to recommend an approach for adequate prediction of the properties of iron-based alloys for a preset composition and mode of heat treatment. Stages of creation (design), testing, production and deployment of high strength alloy steel, include the specification of the chemical composition, the parameters of the mode of thermal treatment and the final mechanical properties. The steel for its components and features for heat treatment is a technological object and therefore it is possible to apply for it an approach for modeling the properties and optimizing the composition depending on the particular application. The procedure of a reasoned elaboration of the chemical composition by the number and the amount of alloying elements is relatively new related to the pursuit of the final mechanical properties. The practical results are applicable and they can be used for: - the design of more efficient compositions in terms of the expensive alloying elements while maintaining the basic properties above a given threshold, evaluation of the technological cost of equally applicable technological variants of varying degrees of doping steel, - determination of a rational representative of a certain class of materials best suited to the requirements previously set (most often controlled properties) among the rest of the class.
\end{abstract}

Keywords: ferrous alloys, modeling and optimization properties, neural models, genetic optimization algorithm

\section{INTRODUCTION}

Artificial Neural Networks (ANN) (Taylor, 1996), and Modeling Perception with Artificial Neural

The address of the corresponding author: Nikolay Tontchev

拝=" tontchev@vtu.bg
Networks (Tosh \& Ruxton, 2010) are very effective as a computational tool for solving problems without any alternative. This is due to the advantage of neural networks over other computing systems that operates with ANN that they work parallel and significantly outrun successive calculations in rapidity. The neural network always operates as a system of 
connected elementary units which are important for the functioning of the network. According to Borovikov (2008), one of the consequences of this kind of activity is the ability to work properly with the destruction of many of its elements (known as 'graceful degradation'). The current trend of increasing use of the ANN leads to complex and intelligent tools for design.

The great amount of metallic materials on iron base ( 99\% from the worldwide production) is construction materials. The conditions for their operation are related to the stress $(R)$, occurring in certain sections. This is the reason all the engineering calculations to be based on the yield strength $\mathrm{Re}$, a tension at which the permanent plastic elongation is $0.2 \%$. For each class of steels with a definite purpose, the user knows the approximate value of the yield strength $R e$ and he/she relates it to many other necessary technological performance properties. Calculations of steel constructions use the tensile strength $(\mathrm{Rm})$, and this is the tension at which they lose their operative size and the configuration for the corresponding load. The ratio shows the resistance of the material to local overloads. All obligatory features (strength $R e$, $\mathrm{Rm}, \mathrm{HB}$ and plastic $\mathrm{A}$ and $\mathrm{Z}$ ) intuitively are considered during the selection of the material due to the controversial action of the various alloying elements on their values. It is difficult to combine high yield strength $(R e)$ with high toughness to destruction.

The basis for the research is a database of 91 alloys (Zubchenko, Koloskov, Kashirskii, \& et al, 2003).

The design of an alloy is based on modeling by neural networks, satisfactorily approximating the relations between the chemical composition of the alloy and the mechanical parameters under fixed heat treatment - hardening and hightemperature annealing

For this purpose the following conditions were applied to modeling:

- Type of neuronal models - the research is focused mainly on classic FF (feedforward) models such as multilayer perceptron (MLP). The study sample of experimental data includes observations of 91 alloys with different compositions and corresponding values of the parameters $R e$ and $A$.

- The research was performed with the specialized software StatSoft Statistica 10 module Artificial Neural Networks (StatSoft, 2013).

- Implementation of the study and results - for each of the studied neural models starting experimental data are divided into three sets: training, test and validation in which the number of observations included is in the ratio respectively $70 \%$ : $15 \%$ : $15 \%$. Observations included in these sets are chosen randomly.

For modeling of the relation between the composition of the alloy and any of the parameters $R m, R e, A, K c u$ and $H B$ there have been examined 1000 separate neural models, differing in their configuration (number of internal neurons) and the activation functions of the neurons from the internal layer and the output layer.

The following activation functions are used for the design of the MLP neural model:

- Identity:

$f(x)=x$,

- Logistic (sigmoid) function:

$$
f(x)=\frac{1}{1-e^{-x}}, \quad f(x)=\frac{e^{x}-e^{-x}}{e^{x}+e^{-x}},
$$

- Exponent:

$$
f(x)=e^{-x} .
$$

The evaluation of the quality of the tested neural models is based on the performance:

- Correlation between observed and modeled values of the output network:

$$
R=\frac{\sum_{i=1}^{N}\left(y_{i}-\bar{y}\right)\left(t_{i}-\bar{t}\right)}{\sqrt{\sum_{i=1}^{N}\left(y_{i}-\bar{y}\right)^{2} \cdot \sum_{i=1}^{N}\left(t_{i}-\bar{t}\right)^{2}}},
$$

where $N$ is the number of elements (observations) per set (instructional, test or 
validation), $y_{i}$ is the calculated output of the network, and $t_{i}$ is the observed value of the approximated parameter, $\bar{y}$ and $\bar{t}$ are the statistical means for modeled and observed output values (for the corresponding set)

- Function of the error - the sum of the squares between observed and modeled values of the output network:

$$
E_{\text {SOS }}=\sum_{i=1}^{N}\left(y_{i}-t_{i}\right)^{2}
$$

wherein the denotations are as above.

Based on the research for each of the parameters $R m, R e, A, K c u$ and $H B$ there were selected neural models having the best indicators of quality ( $R$ and $\left.E_{S O S}\right)$. The data for both selected neural models of the MLP type are shown in Table 1. The table indicates the values of the correlation coefficient $R$ and the error $E_{S O S}$ for the test set, also the type of activation function in the internal (hidden) and output layer of the neural model.

Table1. Neural networks of type MLP, approximating parameter

\begin{tabular}{|c|c|c|c|c|c|}
\hline Parameter & $\begin{array}{c}\text { Type of } \\
\text { the neural } \\
\text { network }\end{array}$ & $\begin{array}{c}\text { Activation } \\
\text { function, } \\
\text { internal layer }\end{array}$ & $\begin{array}{c}\text { Activation function, } \\
\text { output neuron }\end{array}$ & R Test & Esos Test \\
\hline$R m$ & MLP 8-6-1 & Logistic & Tanh & 0.781471 & 12931.86 \\
\hline$R e$ & MLP 8-7-1 & Tanh & Logistic & 0.856995 & 9708.579 \\
\hline A & MLP 8-16-1 & Logistic & Tanh & 0.886477 & 1.514303 \\
\hline Kcu & MLP 8-14-1 & Tanh & Logistic & 0.855329 & 10352.15 \\
\hline HB & MLP 8-4-1 & Tanh & Exponent & 0.972724 & 83.18074 \\
\hline
\end{tabular}

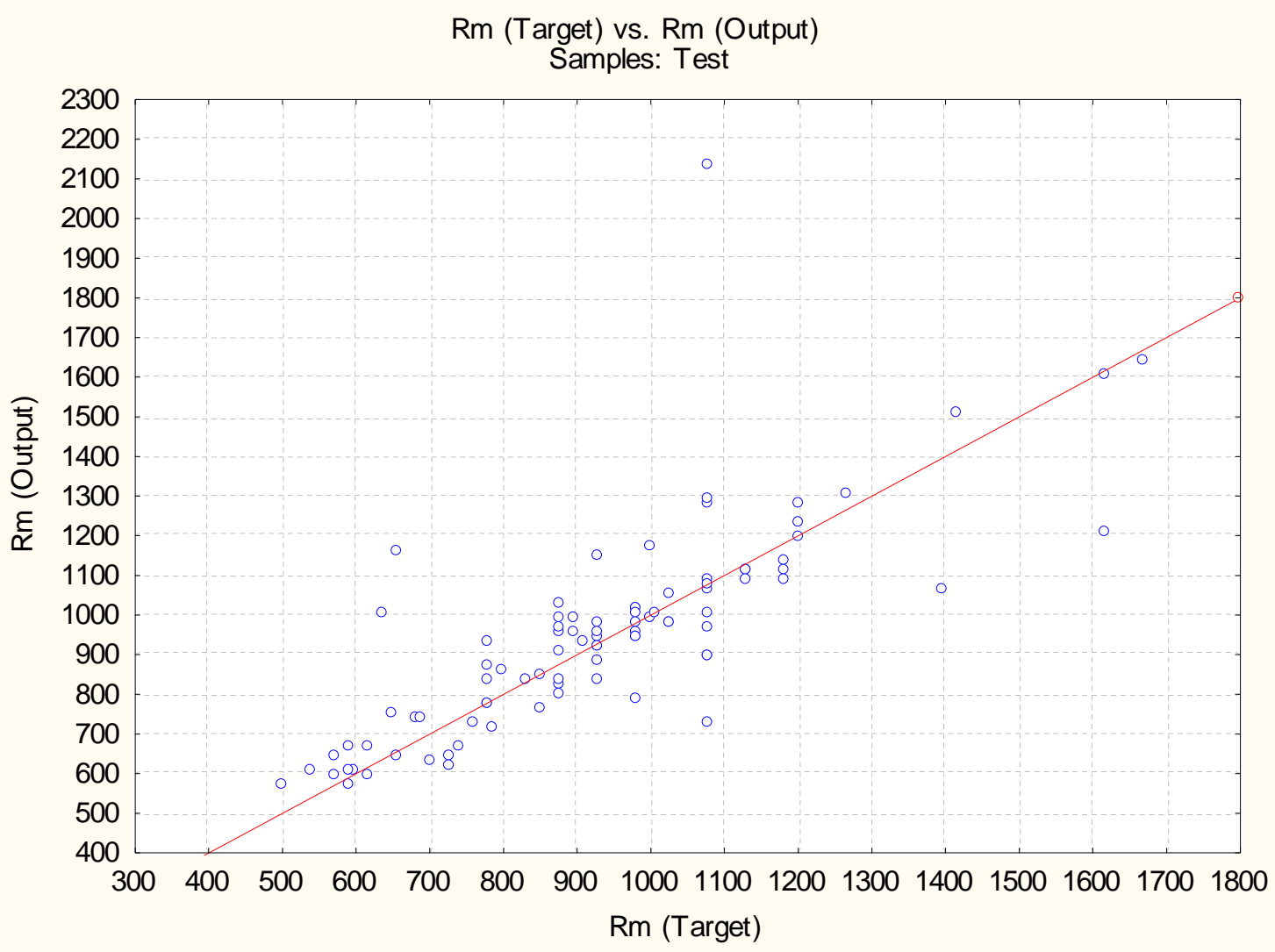

Fig.1 Correlation between observed and modeled values of $\mathrm{Rm}$ 
Tontchev \& Ivanov. Optimization of composition of iron-bases alloys FBIM Transactions Vol.2 No.1 pp.1 - 12

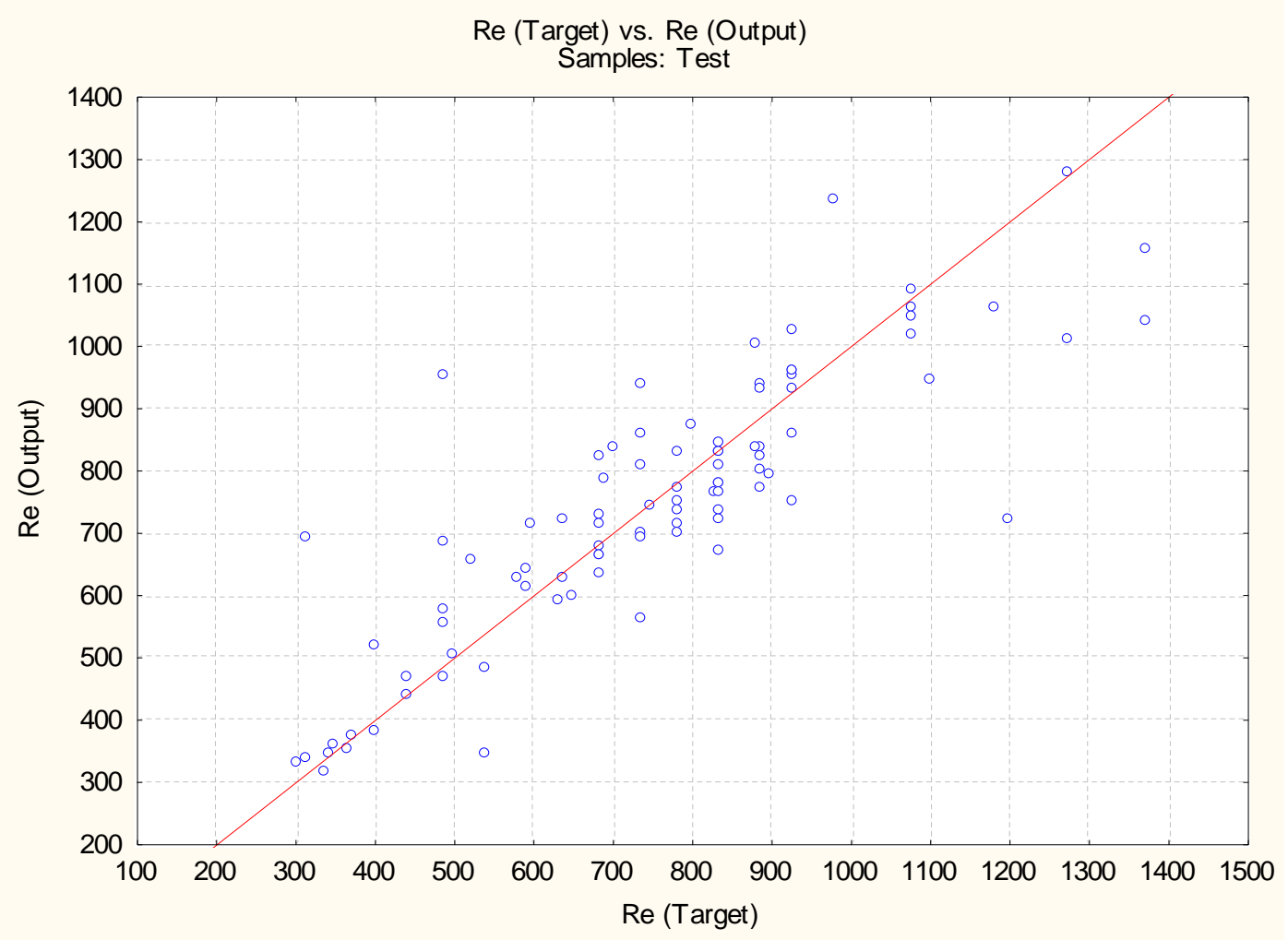

Fig.2 Correlation between observed and modeled values of Re

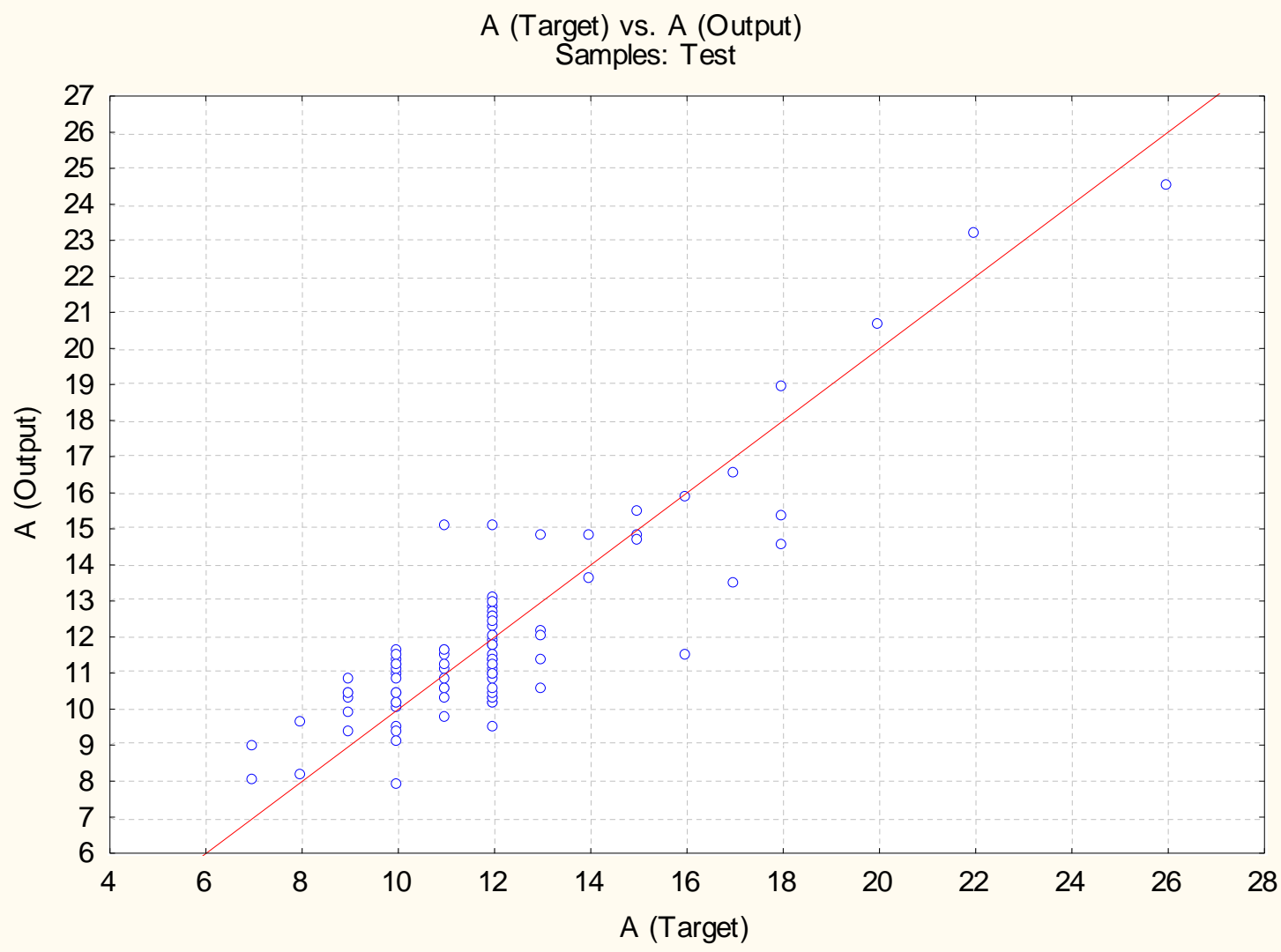

Fig.3 Correlation between observed and modeled values for $A$ 
Tontchev \& Ivanov. Optimization of composition of iron-bases alloys FBIM Transactions Vol.2 No.1 pp.1 - 12

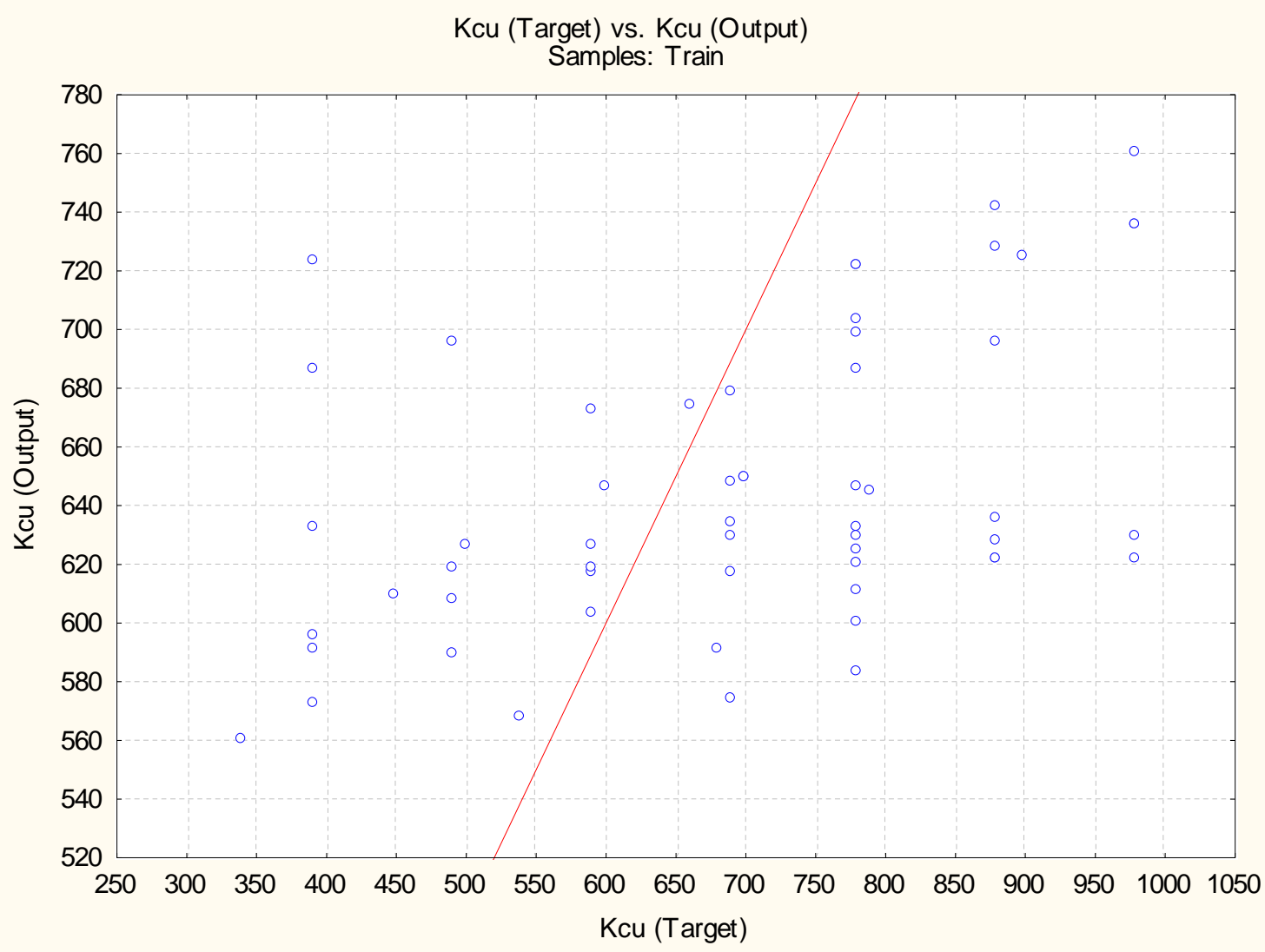

Fig.4. Correlation between observed and modeled values of Kcu

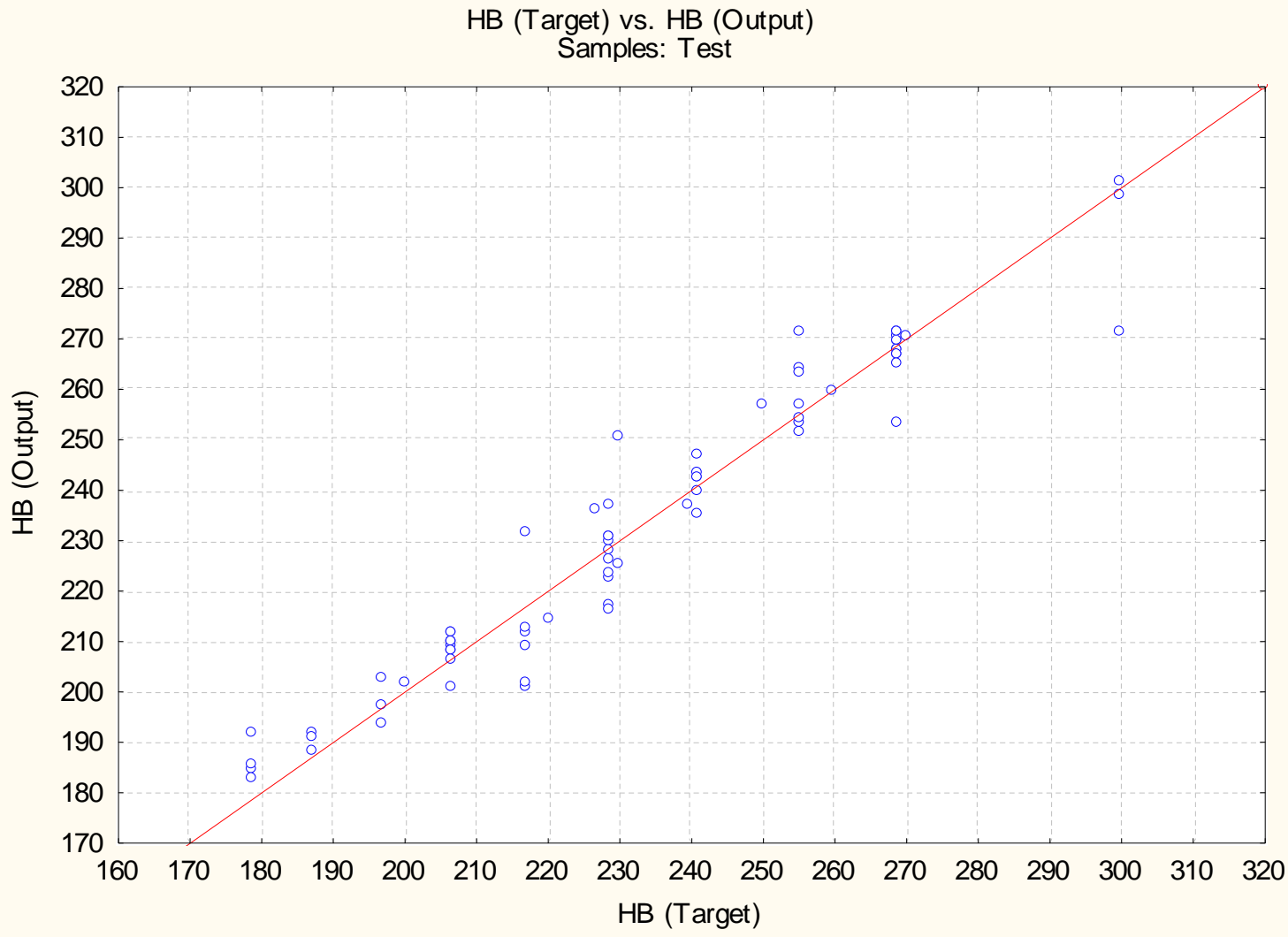

Fig.5. Correlation between observed and modeled values of $H B$ 
Fig. 1 to Fig. 5 show two-dimensional diagrams comparing observed and modeled values of the parameters listed in the tables $R m, R e, A, K c u$ and $H B$ networks.

Based on the evaluation of the quality of the prepared in this way neural models (Freeman $\mathrm{J}$. A., David, Skapura M, 1991, ) it has been accepted that they have sufficiently good approximation properties and that they may be successfully used in experiments and in numerical assignments for modeling and optimization of the composition iron-carbon alloys.

\section{DESCRIPTION OF THE MULTICRITERIA AHP APPROACH}

The approach for multicriteria optimization of the composition for the ferritic alloy is based on three basic postulates:

- using the deduced above neural models for approximation of the explored mechanical properties of the alloy, depending on its chemical composition;

- presentation of the multicriteria assessment of the alloy quality by weight(ed) complex criterion using the AHP (Analytic Hierarchy Process) method. The criterion takes into account the mechanical parameters of the alloy, determined on the basis of neural models and involved in the final criterial assessment by the priority weights.

- using a genetic algorithm to find an optimal chemical composition of the alloy on the basis of the accepted complex criterion.

The optimization problem is formulated in the following form:

- find the maximum of complex optimization criterion:

$$
K=\sum_{j=1}^{m} w_{j} K_{j}^{\prime}(X),
$$

where:

- $X=\left(x_{1}, \ldots, x_{n}\right)$ is the vector of values of the arguments for the problem;

- $K_{j}^{\prime}(X)$ are normalized dimensionless estimates of particular criteria in the form:

$$
K_{j}^{\prime}(X)=\frac{K_{j}(X)-K_{j}^{\min }}{K_{j}^{\max }-K_{j}^{\min }}, j=1, \ldots, m,
$$

$K_{j}^{\mathrm{min}}, \quad K_{j}^{\mathrm{max}}$ are the minimal and maximal values for the criterion $K_{j}, j=1, \ldots, m$, defined by the possible values of $X=\left(x_{1}, \ldots, x_{n}\right)$ in the domain of task $D$, and $K j(X)$ is the value of the private trkushtata criteria for the decision $X ; w_{j}$ are the normalized weights of the private criteria $K j(X)$, involved in the complex criterion $K$.

The constraints on the arguments of the problem determining its domain are of the form:

$$
D:\left\{\begin{array}{l}
x_{i} \in\left[x_{i}^{\min }, x_{i}^{\max }\right] \\
x_{i} \geq 0, i=1, \ldots, n
\end{array}\right.
$$

The strength and plastic characteristics of the alloy have been chosen as a criterion. In models for approximation the elements participate with their percentage: $x_{1}, \ldots, x_{n}$ and the range of variation.

The multicriteria approach is based on the method AHP (Haupt \& Haupt, 2004). The approach is popular for solving similar problems and it is known in that it allows through expertise and simple algebraic calculations to determine the relative weights $w_{i}$ of the private criteria in the general complex criterion. The determination of the weights is made on the basis of the expert's comparison of mutual dominance of private criteria in two by two so-called "Matrix of comparisons" - a reciprocal square-antisymmetric matrix of dimension $m \times m$. In the evaluation of the mutual dominance of criteria are used the values $1,3,5,7$ and 9 , which correspond to an ordinance of increasing degrees of dominance (from "lack of dominance" between the compared criteria to "extreme dominance"). The procedure for calculating the weights $w_{i}$ is based on finding the eigenvector of the largest eigenvalue of the matrix $A$. The detailed and complete description of the AHP method is contained in (Haupt \& Haupt, 2004), (Saaty \& Vargas, 2012), (Bodenhofer, 2000), (Coley, 1999), present computational models based on evolutionary ideas borrowed from biological science. 


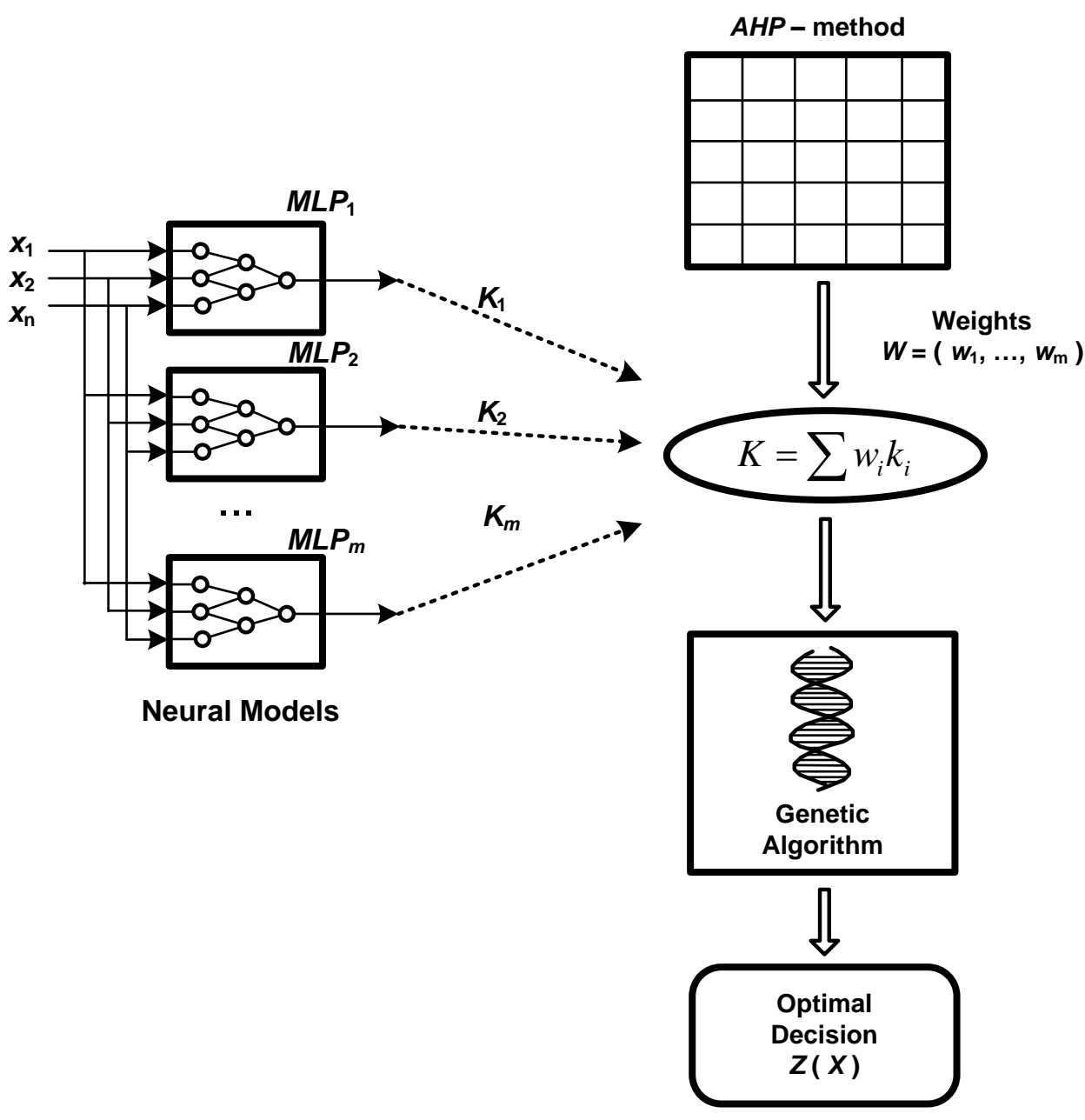

Fig. 6 General scheme of the approach to multicriteria optimization of the composition of the alloy using a genetic algorithm

Their main advantage is the applicability to a wide range of complex optimization problems, where often the relationship between the optimized parameters and optimization criteria is not clearly and formally defined. The solution is sought on a set of feasible solutions to the main problem - ("population" of "individuals") determined mostly by a procedure of random generation. Each individual solution is described by the set of encoded values of the optimization parameters, known as "chromosomes". The optimal solution is sought iteratively till the satisfaction of a given criterion for the termination of the process. The initial population of individuals is evolved due to "crossovers" of chromosomes and a random "mutation" in each iteration. A procedure for selection of the "better" individuals provides the practical convergence of the decision (albeit slowly) to the area of global minimum. In the particular problem the initial population of possible alloy compositions is generated as a set of points randomly distributed in the domain $D$ (200 in total). The chemical composition of the material is contained in coded form in the "chromosomes" of randomly generated solutions. In the research there has been used the so-called "tournament" approach for the selection of crossover-promising "individuals." The random mutation is performed after the crossover with a probability of 0.08 . The used algorithm is implemented in C-language code selecting effective techniques from issued implementations of algorithms from this class.

The ultimate value of the complex criterion $K$ was prepared as a dimensionless quantity in the range of $(0,1)$. 
Tontchev \& Ivanov. Optimization of composition of iron-bases alloys

FBIM Transactions Vol.2 No.1 pp.1 - 12

\section{DESCRIPTION OF NUMERICAL EXPERIMENT}

The numerical experiment was carried out with several examples, two of which (labeled $\mathbf{A}$ and $\mathbf{B}$ ) are presented here. The examples include as initial data various matrices of comparisons for the private criteria necessary to calculate the weights $w_{i}, i=1, \ldots, n$ in which they participate in the complex optimization criterion $K$. The values in the matrices are determined through an expertise according to the methodology for the application of the AHP-method. Table 2 and Table 3 present a comparison between the matrices of sample $\mathbf{A}$ and sample $\mathbf{B}$.

Table 2 Estimates of prevalence in the matrix of the criteria for comparisons, for example A

\begin{tabular}{|c|c|c|c|c|c|}
\hline & $\mathbf{R m}$ & $\mathbf{R e}$ & $\mathbf{A}$ & $\mathbf{K C U}$ & HB \\
\hline $\mathbf{R m}$ & 1 & $1 / 5$ & $1 / 3$ & 3 & 5 \\
\hline $\mathbf{R e}$ & 5 & 1 & 3 & 7 & 9 \\
\hline $\mathbf{A}$ & 3 & $1 / 3$ & 1 & 5 & 7 \\
\hline $\mathbf{K C U}$ & $1 / 3$ & $1 / 7$ & $1 / 5$ & 1 & 1 \\
\hline $\mathbf{H B}$ & $1 / 5$ & $1 / 9$ & $1 / 7$ & 1 & 1 \\
\hline
\end{tabular}

Table 3 Estimates of prevalence in the matrix of the criteria for comparisons, for example $B$

\begin{tabular}{|c|c|c|c|c|c|}
\hline & $\mathbf{R m}$ & $\mathbf{R e}$ & $\mathbf{A}$ & $\mathbf{K C U}$ & $\mathbf{H B}$ \\
\hline $\mathbf{R m}$ & 1 & $1 / 3$ & $1 / 5$ & 5 & 7 \\
\hline $\mathbf{R e}$ & 3 & 1 & $1 / 3$ & 7 & 9 \\
\hline $\mathbf{A}$ & 5 & 3 & 1 & 5 & 7 \\
\hline $\mathbf{K C U}$ & $1 / 5$ & $1 / 7$ & $1 / 5$ & 1 & 3 \\
\hline $\mathbf{H B}$ & $1 / 7$ & $1 / 9$ & $1 / 7$ & $1 / 3$ & 1 \\
\hline
\end{tabular}

Table 4 Weights $w_{i}$ of the test criteria, after the application of the procedure of the AHP-method for example $A$ and for example $B$

\begin{tabular}{|c|c|c|}
\hline Criterion & $\begin{array}{c}\text { Weights for } \\
\text { example A }\end{array}$ & $\begin{array}{c}\text { Weights for } \\
\text { example B }\end{array}$ \\
\hline $\mathbf{R m}$ & 0.130356 & 0.153374 \\
\hline $\mathbf{R e}$ & 0.515726 & 0.286948 \\
\hline $\mathbf{A}$ & 0.262767 & 0.47138 \\
\hline $\mathbf{K C U}$ & 0.0502754 & 0.0572825 \\
\hline $\mathbf{H b}$ & 0.0408753 & 0.0310152 \\
\hline
\end{tabular}

The result of the processing based on the above matrix weights $w_{i}$ of the private criteria after applying the procedure of AHP-method for example $\mathbf{A}$ and for example $\mathbf{B}$ are shown in Table 4.

The values of the complex criterion $K$ after optimization with the genetic algorithm, the optimal composition of the alloy $X^{*}=\left(x_{1}^{*}, \ldots, x_{n}^{*}\right)$ for the so-selected weights $w_{i}$, and the value of the private optimization criteria $K_{j}, j=1, \ldots, m$ are shown in Table 5.

Table 5 Values of the complex criterion

\begin{tabular}{|c|c|}
\hline For example A & For example B \\
\hline 0.82826150333 & 0.76458389405 \\
\hline
\end{tabular}

The optimal composition from the considered procedure of the specified requirements about the mechanical properties is shown in Table 6 .

Table 6 Result of the applied optimization procedure

\begin{tabular}{|l|r|r|}
\hline $\begin{array}{l}\text { Input-output } \\
\text { parameters }\end{array}$ & $\begin{array}{c}\text { Composition } \\
\text { and } \\
\text { properties for } \\
\text { example A }\end{array}$ & $\begin{array}{c}\text { Composition } \\
\text { and } \\
\text { properties for } \\
\text { example B }\end{array}$ \\
\hline C [\%] & 0.479 & 0.473 \\
\hline Si [\%] & 1.399 & 1.380 \\
\hline Mn [\%] & 0.270 & 0.291 \\
\hline Ni [\%] & 1.911 & 0.220 \\
\hline S/P [\%] & 0.015 & 0.015 \\
\hline Cr [\%] & 3.250 & 3.235 \\
\hline Mo[\%] & 0.688 & 0.616 \\
\hline $\mathbf{V}$ [\%] & 0.0003 & 0.009 \\
\hline $\mathbf{R m}$ [MPa] & 1435.026 & 1431.566 \\
\hline $\mathbf{R e}[\mathbf{M P a}]$ & 1348.571 & 1341.013 \\
\hline $\mathbf{A} \%]$ & 20.213 & 20.100 \\
\hline KCU [kJ/m ${ }^{2}$ ] & 945.0369 & 942.8902 \\
\hline HB [MPa] & 271.06 & 271.06 \\
\hline
\end{tabular}

Table 7 shows the result from the influence of carbon on the optimization solution. The analysis of the composition and the results for the tested properties manifest a very stable behavior. 
Tontchev \& Ivanov. Optimization of composition of iron-bases alloys FBIM Transactions Vol.2 No.1 pp. 1 - 12

Table 7. Research of the influence of carbon content on the optimization solution

\begin{tabular}{|c|c|c|c|c|}
\hline $\begin{array}{c}\text { Input-output } \\
\text { parameters }\end{array}$ & Solution \#1 & Solution \#2 & Solution \#3 & Solution \#4 \\
\hline $\mathbf{C}[\%]$ & 0.3 & 0.35 & 0.4 & 0.42 \\
\hline $\mathbf{S i}[\%]$ & 1.39 & 1.4 & 1.39 & 1.39 \\
\hline $\mathbf{M n}[\%]$ & 0.46 & 0.52 & 0.46 & 0.388 \\
\hline $\mathbf{N i}[\%]$ & 2.2 & 1.54 & 1.58 & 1.68 \\
\hline $\mathbf{S} / \mathbf{P}[\%]$ & 0.019 & 0.016 & 0.015 & 0.015 \\
\hline $\mathbf{C r}[\%]$ & 3.25 & 3.235 & 3.24 & 3.25 \\
\hline $\mathbf{M o [ \% ]}$ & 0.47 & 0.53 & 0.61 & 0.647 \\
\hline $\mathbf{V}[\%]$ & 0.0003 & 0.0 & 0.0001 & 0.0009 \\
\hline $\mathbf{R m}[\mathbf{M P a}]$ & 1372.11 & 1387.0 & 1405.5 & 1407.0 \\
\hline $\mathbf{R e}[\mathbf{M P a}]$ & 1292.57 & 1304.0 & 1316.0 & 1322.0 \\
\hline $\mathbf{A}[\%]$ & 18.37 & 18.8 & 19.48 & 19.76 \\
\hline $\mathbf{K C U}\left[\mathbf{k J} / \mathbf{m}^{2}\right]$ & 932.33 & 945.13 & 956 & 961 \\
\hline $\mathbf{H B}[\mathbf{M P a}]$ & 271 & 271 & 271 & 271 \\
\hline
\end{tabular}

The basis for further research is the chemical composition of solution \# 2. The composition is fixed as it follows: $\mathrm{C}=0.35 \% ; \mathrm{Si}=1.4 \% ; \mathrm{Mn}=$
$0.52 \% ; \mathrm{S}$ and $\mathrm{P}=0.016 \% ; \mathrm{Mo}=0.53 \% ; \mathrm{V}=0 \%$, and in Table 8 there are presented the results for the tested parameters for the variation of nickel and chromium.

Table 8 Research of the influence of nickel and chromium on the optimization solution

\begin{tabular}{|c|c|c|c|c|c|c|c|}
\hline № & $\mathbf{N i}$ & $\mathbf{C r}$ & $\mathbf{R m}$ & $\mathbf{R e}$ & $\mathbf{A}$ & $\mathbf{K C U}$ & HB \\
\hline 1 & 1.542 & 3.25 & 1388.82 & 1304.29 & 18.80 & 946.09 & 271.05 \\
\hline 2 & 1.542 & 3 & 1368.24 & 1299.01 & 18.86 & 952.23 & 271.02 \\
\hline 3 & 1.542 & 2.5 & 1336.4 & 1281.36 & 18.63 & 947.67 & 270.73 \\
\hline 4 & 1.542 & 2 & 1337.48 & 1247.82 & 17.82 & 914.80 & 268.25 \\
\hline 5 & 1.542 & 1.5 & 1383.56 & 1186.91 & 16.39 & 824.65 & 252.14 \\
\hline 6 & 2.2 & 3.25 & 1443.71 & 1290.21 & 18.87 & 741.34 & 271.05 \\
\hline 7 & 2.2 & 3 & 1429.61 & 1280.80 & 18.89 & 762.88 & 271.04 \\
\hline 8 & 2.2 & 2.5 & 1405.66 & 1249.95 & 18.58 & 793.80 & 270.87 \\
\hline 9 & 2.2 & 2 & 1401.26 & 1193.02 & 17.67 & 778.19 & 269.45 \\
\hline 10 & 2.2 & 1.5 & 1430.45 & 1096.76 & 16.20 & 697.52 & 258.99 \\
\hline 11 & 1 & 3.25 & 1323.69 & 1312.06 & 18.73 & 973.25 & 271.04 \\
\hline 12 & 1 & 3 & 1296.9 & 1308.97 & 18.81 & 974.14 & 271.00 \\
\hline 13 & 1 & 2.5 & 1261.16 & 1298.18 & 18.65 & 970.81 & 270.53 \\
\hline 14 & 1 & 2 & 1274.23 & 1277.18 & 17.92 & 953.02 & 266.68 \\
\hline 15 & 1 & 1.5 & 1340.67 & 1237.84 & 16.56 & 888.81 & 244.91 \\
\hline
\end{tabular}




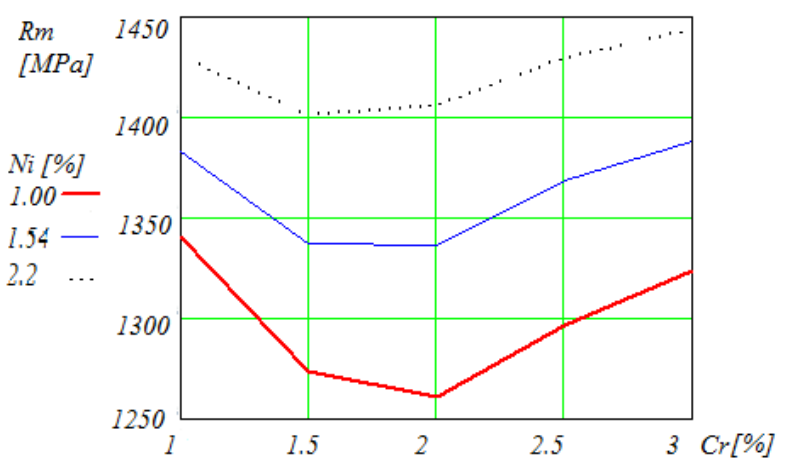

Fig. 6 Variation in tensile strength with the variation of chromium and nickel in the optimal composition set

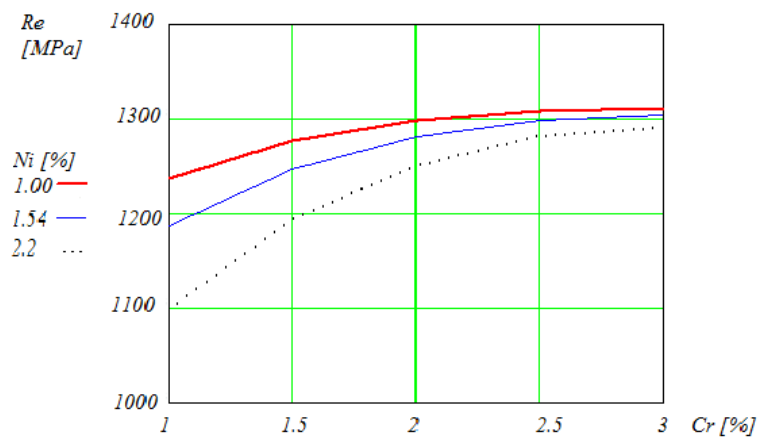

Fig. 7 Amendment of the yield point for variations of chromium and nickel in the optimally defined composition

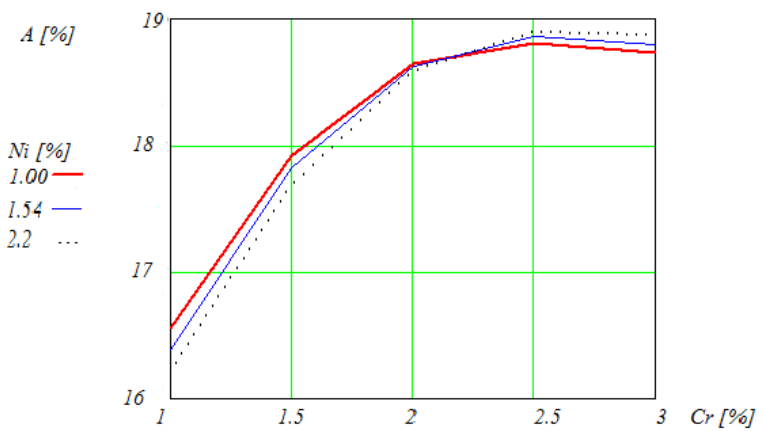

Fig. 8 Modification of the variation in the elongation of chromium and nickel in the optimally defined composition
Figures 6 to 8 present graphical interpretations of the results from Table 8 for variances with chromium and nickel.

\section{CONCLUSIONS}

The optimization approach is based on the selection of neural models for approximation of the physical and mechanical parameters $R m, R e$, $A, K c u$ and $H B$. A significant number (more than 1000 ) of various neural models with a different number of nodes in the hidden layer and different activation functions is the object of research. There have been selected only the neural patterns with the best quality of approximation;

Use of an multicriteria approach taking into account the mutual dominance of the criteria and with an evaluation of the normalized weights with which they are engaged in the complex optimization criterion. The weights of the private criteria may be modified to suit the specific needs and preferences of the designer, according to the intended purpose of the iron-carbon alloy.

Usage of a universal and flexible optimization algorithm based on the genetic approach. Practically the algorithm is independent of the approximative nature of the connections for the private criteria; it does not depend on the structure and type of the complex optimization criterion. The algorithm can be used in a very wide range of conditions and requirements related to the properties of the material.

The approach and the formulated model can be widely used in research with practical choice of materials and their composition, as well as for training of experts in the respective engineering field.

\section{Works Cited}

Bodenhofer, U. (2000). Genetic Algorithms:Theory and Applications, Lecture Notes. (Second Edition WS 2001/2002). Linz, Austria. Retrieved from http://www4.hcmut.edu.vn/ hthoang/dktm/GA\%20Theory\%20and\%20Application.pdf

Borovikov, V. (2008). Nejronnye seti. Metodologija i tehnologii sovremennogo analiza dannyh (2 ed.). (V. Borovikov, Ed.) Gorjachaja linija - Telekom.

Coley, D. A. (1999). An Introduction To Genetic Algorithms For Scientistsand Engineers. Singapore: World Scientific Publishing Co. Pte. Ltd. 
Haupt, R. L., \& Haupt, S. E. (2004). Practical genetic algorithms (Second Edition ed.). John Wiley \& Sons, Inc.

Saaty, T. L., \& Vargas, L. G. (2012). Models, Methods, Concepts and Applications of the Analytic Hierarchy Process (Vol. 175). New York - Heidelberg - Dordrecht - London: Springer. doi:10.1007/978-1-4614-3597-6

StatSoft. (2013). Model Extremly Complex Functions, Neural Networks. Retrieved 09 05, 2013, from StatSoft: http://www.statsoft.com/textbook/

Taylor, J. G. (1996). Neural Networks and Their Applications. (J. G. Taylor, Ed.) West Sussex, England, United Kingdom: John Wiley and Sons.

Tosh, C. R., \& Ruxton, G. D. (2010). Modelling Perception with Artificial Neural Networks. Cambridge, United Kingdom: Cambridge University Press 2010.

Zubchenko, A. S., Koloskov, M. M., Kashirskii, Y. V., \& et al. (2003). List of Grades of Steels and Alloys [in Russian] (2nd ed.). Moscow, Russia: Mashinostroenie.

\section{ACKNOWLEDGMENTS}

This work was partially supported by the Bulgarian National Science Fund under the Project No DDVU 02/11 "Characteristic modeling and composition optimization of iron-base alloys used in machinebuilding industry"

Received for publication: $\quad 05.09 .2013$

Revision received: $\quad 30.09 .2013$

Accepted for publication: $\quad 21.12 .2013$

\section{How to cite this article?}

Style - APA Sixth Edition:

ontchev, N., \& Ivanov, M. (2014, 01 15). Modeling and optimization of the composition of iron-based alloys by approximation with neural models and genetic optimization algorithm. (Z. Čekerevac, Ed.) FBIM Transactions, 2(1), 1-12. doi:10.12709/fbim.02.02.01.01

Stile - Chicago Fifteenth Edition

Tontchev, Nikolay, and Martin Ivanov. "Modeling and optimization of the composition of iron-based alloys by approximation with neural models and genetic optimization algorithm." Edited by Zoran Čekerevac. FBIM Transactions (MESTE) 2, no. 1 (01 2014): 1-12.

Style - GOST Name Sort:

Tontchev Nikolay and Ivanov Martin Modeling and optimization of the composition of iron-based alloys by approximation with neural models and genetic optimization algorithm [Journal] = Optimization of composition of iron-bases alloys // FBIM Transactions / ed. Čekerevac Zoran. - Belgrade : MESTE, 01 15, 2014. - 1 : Vol. 2. - pp. 1-12. - ISSN 2334-704X (Online); ISSN 2334-718X;. 


\section{Style - Harvard Anglia:}

Tontchev, N. \& Ivanov, M., 2014. Modeling and optimization of the composition of iron-based alloys by approximation with neural models and genetic optimization algorithm. FBIM Transactions, 15 01, 2(1), pp. 1-12.

Style - ISO 690 Numerical Reference:

Modeling and optimization of the composition of iron-based alloys by approximation with neural models and genetic optimization algorithm. Tontchev, Nikolay and Ivanov, Martin. [ed.] Zoran Čekerevac. 1, Belgrade : MESTE, 01 15, 2014, FBIM Transactions, Vol. 2, pp. 1-12. ISSN 2334-704X (Online); ISSN 2334-718X; 